\title{
A CARNALIDADE DE OUTREM E O LOGOS DO MUNDO estético em Merleau-Ponty
}

\author{
Rodrigo Alvarenga ${ }^{1}$
}

\begin{abstract}
Resumo: A questão da intersubjetividade está presente ao longo de toda a obra de Merleau-Ponty, desde A estrutura do comportamento, a partir do debate com a psicologia e a fisiologia clássicas, até a ontologia indireta, focalizada em $O$ visivel e o invisivel. Suas teses evidenciam um aprofundamento em direção à carnalidade de outrem, enquanto experiência de um estranho/familiar, que é central para se compreender a possibilidade da intersubjetividade e da experiência estética do mundo. Desse modo, o presente estudo visa a compreender a forma como Merleau-Ponty desenvolveu sua teoria da intersubjetividade, na última fase de seu pensamento, considerando a aproximaçấo existente entre a experiência de outrem e a experiência artística, com base no Logos do mundo estético.
\end{abstract}

Palavras-chave: Alteridade. Arte. Carne. Outrem.

\section{INTRODUÇÃo}

Em O visivel e o invisivel, Merleau-Ponty dá continuidade a suas reflexões sobre a questão da alteridade, explorando um modo de explicar o fenômeno da apresentação de outrem, de forma que não se constitua a partir da atividade da consciência, o que leva à necessidade de explicar melhor a carnalidade da experiência sensível do mundo. Procurando ir além de Husserl e sua teoria da intersubjetividade transcendental, por meio da qual a constituição do ego e do alter ego é possível, em função do acoplamento/emparelhamento (Paarung), gênese da atividade constitutiva, Merleau-Ponty retoma essa problemática, afirmando que a consciência de si e de outrem não são derivadas de uma atividade constituinte. A questão da intersubjetividade, portanto, passa a ser

${ }^{1}$ Programa de Pós-Graduação em Direitos Humanos e Políticas Públicas da Pontifícia Universidade Católica do Paraná (PUCPR), Curitiba, PR - Brasil. (iD https://orcid.org/0000-0001-8546-4442. E-mail: alvarenga.rodrigo@pucpr.br.

http://dx.doi.org/10.1590/0101-3173.2020.v43n4.20.p313

This is an open-access article distributed under the terms of the Creative Commons Attribution License. 
explicada por meio de uma teoria mais fundamental da gênese constitutiva do fenômeno da correlação, ou seja, da aparição do mundo para a consciência.

$\mathrm{O}$ texto de $A$ prosa do mundo e o projeto relacionado à busca de uma gênese da verdade, no interior da linguagem, são deixados de lado, e a discussão é deslocada do plano fenomenológico para o plano ontológico. Contudo, não se trata de um abandono desse projeto, uma vez que, segundo Lefort (2010), não fosse a morte prematura do filósofo, seria bem provável que $A$ prosa $d o$ mundo e $O$ visivel e o invisivel fizessem parte de uma mesma obra. Assim, é a procura do entendimento dos enigmas da linguagem, náo compreensíveis plenamente pela análise da própria linguagem, que conduz Merleau-Ponty ao plano ontológico.

Em $O$ visivel e o invisivel, Merleau-Ponty reconhece que a noção de cogito tácito, desenvolvida na Fenomenologia da percepçâo, ainda era oriunda de um resquício em seu pensamento das filosofias da consciência e do solipsismo, pois a unidade temporal do sensível, a aparição do mundo e de outrem para a consciência, permanecia dependente do eu transcendental. Merleau-Ponty começará a perceber, pelos estudos sobre a linguagem e a intersubjetividade no fenômeno da comunicação, que não é possível expressar pela linguagem a camada existencial a partir da qual ela nasce. O filósofo deu-se conta de que pressupor um cogito tácito é fazer permanecer o privilégio da subjetividade constituinte sobre outrem:

O que chamo cogito tácito é impossível. Para possuir a ideia de 'pensar' (no sentido de 'pensamento de ver e de sentir'), para fazer a 'redução', para retornar a imanência e a consciência de... é preciso possuir as palavras. É graças a combinaçáo de palavras (com sua carga de significaçôes sedimentadas e capazes, por princípio de entrar em outras relaçóes diferentes das relações que serviram para formá-las) que opero a atitude transcendental, que constituo a consciência constituinte. (MERLEAUPONTY, 2011, p. 222-223, grifo do autor).

Porém, o que explica essa tomada de consciência do problema, no sentido de que pressupor o cogito tácito é incidir no pressuposto do solipsismo e da filosofia da consciência? Segundo Thierry (1987, p. 70), "a resposta nos parece residir no tratamento da intersubjetividade”, porque é por ela que se evidencia o afastamento do ego transcendental husserliano, na medida em que o mundo vivido, dos últimos trabalhos de Husserl, é considerado por Merleau-Ponty "um mundo no qual outrem é dado como tal com evidência" 
(THIERRY, 1987, p. 71). A investigação que levou a essa conclusão consistiu em buscar um aprofundamento dessa camada pré-reflexiva, a partir da linguagem e da noção de verdade implícita no fenômeno da comunicação. Foi pela realização desse trabalho que o filósofo radicalizou seu pensamento em direção a uma ontologia, afastando-se assim da ideia do cogito tácito como condição de possibilidade da experiência subjetiva e intersubjetiva.

Trata-se de radicalizar o retorno a esse mundo inter-humano, pelo qual se descobriram as possibilidades do poder da comunicação, a fim de compreender mais profundamente a dimensão em que outrem se revela como familiar e ao mesmo tempo estranho. A ideia é investigar "o local geométrico das projeçóes e introjeçôes, a charneira invisível sobre a qual a minha vida e a vida dos outros giram para balouçar de uma para outra a membrura da intersubjetividade" (MERLEAU-PONTY, 2011, p. 283).

Assim, a questão da alteridade em Merleau-Ponty não será mais trabalhada no sentido de buscar nas vivências da consciência o local privilegiado onde se encontra a constituição de outrem, mas investigada na perspectiva da doação originária, em função da qual o mundo e outrem aparecem à consciência em uma dimensão espacial e temporal. Por isso, uma ontologia do sensível, condição do Ser bruto, espécie de realidade que se impóe como substrato de toda elaboraçáo conceitual, no sentido do que ainda não foi submetido a uma ideia. "O ser bruto ou selvagem que não foi ainda convertido em objeto de visão ou de escolha” (MERLEAU-PONTY, 2008, p. 53). Trata-se de uma região do Ser que escapa a qualquer tipo de esforço de dominação racional, por isso, também considerada como selvagem, visto que não é posta pelo ego racional, pois ele mesmo se constitui como desdobramento.

Daí o sentido do questionamento de Merleau-Ponty (2011, p. 261): "como é que se pode regressar dessa percepção moldada pela cultura à percepção bruta ou selvagem?” Para realizar esse movimento em direção à camada originária subentendida pelos atos da consciência, é necessário, primeiramente, admitir a possibilidade dessa região que os transcende, ou seja, é preciso reencontrar-se com a experiência mais original do mundo, com o silêncio a partir do qual são possíveis a intersubjetividade e a criação artística, o Logos do mundo estético e sua manifestação como temporalidade. 


\section{A CARnalidade De OUTREM E TEMPORALIDADE}

Para compreender a questão da alteridade, de modo a não pressupor o ego e o alter ego como duas positividades e náo cair nas armadilhas do objetivismo e do subjetivismo, é necessário compreender esse rompimento com o silêncio, que, por uma espécie de deiscência, inaugura os atos de significação, sem romper o contato com ele:

É como se a visibilidade que anima o mundo sensível emigrasse, não para fora do corpo, mas para outro corpo menos pesado, mais transparente, como se mudasse de carne, abandonando a do corpo pela da linguagem, e assim se libertasse, embora sem emancipar-se inteiramente de toda condição. (MERLEAU-PONTY, 2011, p. 198).

A deiscência é, então, o conceito utilizado para tentar explicar esse desdobramento do ser, pelo qual se coloca a si mesmo diante do espelho, no sentido de uma reflexáo, porém, que nunca pode ser completamente transparente a si. Derivado da botânica, o termo deiscência, em seu sentido científico, define o processo pelo qual os órgãos vegetais atingem o estado de maturação, como no caso da constituição do fruto, o qual pode ser considerado deiscente, quando se abre para oferecer sementes, e indeiscente, cuja semente fica contida no interior do fruto. Na perspectiva de Merleau-Ponty (2011), trata-se da abertura do corpo para ele mesmo, por uma espécie de ruptura e ao mesmo tempo imbricação entre o corpo vidente e o corpo visível, que impede de pensar o transcendental pelo primado da consciência. A relação entre o mundo e o mundo da fala não acontece simplesmente por uma ação do pensamento, já que a realidade pela qual se procura exprimir pela linguagem é plena de sentido. Esse ato não instaura a significação: ela já está lá no sensível, enquanto condição do ser bruto. Desse modo, é preciso pensar o rompimento do silêncio pela fala, com base na reversibilidade, a qual "se manifesta tanto através de uma existência quase carnal da ideia quanto por uma sublimação da carne” (MERLEAU-PONTY, 2011, p. 200).

Será então por meio do conceito de carne que Merleau-Ponty irá procurar desenvolver uma ontologia indireta, a fim de traduzir a experiência de entrelaçamento ou quiasma entre eu e outrem, enquanto experiências distintas do mesmo ser. "Nós nos colocamos tal como o homem natural, em nós $e$ nas coisas, em nós e no outro, no ponto onde por uma espécie de quiasma, tornamo-nos os outros e tornamo-nos mundo" (MERLEAU-PONTY, 2011, p. 210, grifo do autor). O acesso ao que o filósofo chama de ser selvagem se 
dá pelo entrelaçamento intercorporal com o mundo e com os outros, por uma correspondência profunda entre os diferentes seres que fazem parte da mesma carne do mundo. Segundo Falabretti (2013, p. 335), "a estruturalidade como carne somente poderia ser compreendida em virtude de uma deiscência - fissão e identificação - na qual os corpos, as coisas e outro formam uma Gestalt."

A noção de carne diz respeito a uma espécie de elemento no sentido utilizado pelos filósofos da natureza, "meio caminho entre o indivíduo espáciotemporal e a ideia, espécie de princípio encarnado que importa um estilo de ser em todos os lugares onde se encontra uma parcela sua. Nesse sentido, a carne é um 'elemento' do ser" (MERLEAU-PONTY, 2011, p. 182). Pela vivência carnal se correspondem ego e alter ego como habitantes do mesmo tecido do mundo, e se torna possível falar em identidade e diferença, familiaridade e estranhamento ou, ainda, visível e invisível. Como é afirmado nas Notas dos Cursos ao Collége de France (1959-1961), a condição de ser no mundo já não é apenas uma metáfora, visto que o corpo e mundo são feitos do mesmo estofo sensível. Nem naturalismo, nem antropologia são suficientes para explicar esse magma pelo qual os homens e a natureza existem, enquanto partes totais do mesmo ser (MERLEAU-PONTY, 1996).

Não sendo a carne a uniáo ou a composição de duas substâncias, mas uma noção última pela qual o visível e o invisível estão entrelaçados um no outro, abre-se caminho para uma intercorporeidade, pois o visível, enquanto paisagem de um sujeito, também é alguma outra coisa, o que garante a possibilidade de outras paisagens a outros sujeitos (MERLEAU-PONTY, 2011). Na experiência das mãos que se tocam, quando a mão esquerda toca a direita que está em contato com outra coisa exterior, há, por um instante, uma experiência de reversibilidade do sentiente-sensível, a qual pode ser extrapolada para o aperto de mão com o outro. A questão é colocada por Merleau-Ponty (2011) nos seguintes termos:

Cada palpação de uma única mão, embora tenha seu visível e seu tangível, está ligada à outra visão, à outra palpação, de modo a realizar com elas a experiência de um único corpo diante de um único mundo, graças a uma possibilidade de reversão, de reconversão de sua linguagem na delas, possibilidade de reportar e revirar segundo a qual o pequeno mundo privado de cada um não se justapóe àquele de todos os outros, mas é por ele envolvido, colhido dele, constituindo, todos juntos, Sentiente em geral, diante de um Sensível em geral. Ora, essa generalidade que faz a unidade de meu corpo, porque náo se abriria elas a outros corpos? [...]. Porque não 
existiria a sinergia entre diferentes organismos, já que é possível no interior de cada um? (MERLEAU-PONTY, 2011, p. 184-185).

Partindo desse pressuposto, não é apropriado referir-se à percepção das cores ou de uma paisagem como algo pessoal e inconcebível por outro sujeito, como se nunca fosse possível traduzir tal experiência a uma consciência que não a própria. $\mathrm{Na}$ verdade, basta uma referência a respeito do mundo percebido, para que, em função dessa vivência intercorporal da mesma carne do mundo, outros possam vivenciar o sentido daquela experiência, "e isso pela fundamental fissão ou segregação do sentiente e do sensível, que, lateralmente, faz os órgãos de meu corpo entrarem em comunicação, fundando a transitividade de um corpo a outro" (MERLEAU-PONTY, 2011, p. 186). Se, para Merleau-Ponty, a intercorporeidade se fundamenta nesse quiasma, isso não quer dizer que já não exista mais nada de estranho nessa experiência: muito pelo contrário, embora haja essa correspondência entre os visíveis, existe sempre uma invisibilidade de si para consigo mesmo e para com o mundo.

De acordo com Johnson (1990, p. 21), o "próprio corpo prefigura esse contato e divergência com o outro, pois quando uma mão toca a outra o sujeito é para si mesmo já um outro". Mantém-se, portanto, um estranhamento nas relaçóes com o mundo e com outrem, uma vez que no próprio eu reside um invisível para si mesmo. Segundo Merleau-Ponty (2011, p. 186), é essa característica inesgotável do visível "que torna possível sua abertura a outras visões além da minha”. Outrem, por conseguinte, não é uma extensão da consciência individual ou do corpo próprio e nem uma alteridade no sentido pleno, mas é um visível que guarda uma invisibilidade. Enquanto visível, possui a existência corporal pela qual está em contato com o mundo e, por apresentar-se como um fundo inesgotável e invisível, existe como sujeito intencionalmente consciente.

Por isso, a possibilidade de relaçóes intercorporais depende da coincidência entre o eu e o outrem, enquanto carne do mesmo mundo, e dessa "invisibilidade de nós mesmos como videntes, a invisibilidade de um olhar outro que me atinge sem que eu tenha condiçóes de dizer de onde tenha partido [...]” (MÜLLER-GRANZOTTO, 2010, p. 331). É através dessa reversibilidade, desse quiasma pelo qual o para si e o para outrem são apenas a outra face um do outro, que Merleau-Ponty acredita poder explicar a questáo da alteridade. Assim, conforme nota inédita de 1959, extraída dos manuscritos depositados na Biblioteca Nacional da França, o cogito se fundamenta no sentir 
dessa experiência: "não é, portanto, surpreendente, que o cogito de outrem seja ele também derivado da aparição de outrem como carne do sensível no mundo"(MERLEAU-PONTY, 2013a, n.p.). ${ }^{2}$

Nessa perspectiva, não precisa haver privilégio do eu em detrimento de outrem, no que diz respeito à questáo da gênese constitutiva e da intersubjetividade, visto que ambos são perpassados pela experiência transcendental do tempo. Aquilo que se manifesta enquanto experiência de outrem náo pode ser explicado por meio de um ato da consciência; na verdade, isso é o que compromete ou impossibilita uma explicação sobre a intersubjetividade que não caia na atitude solipsista de fazer de si mesmo o centro da experiência do mundo e de outrem. É preciso colocar "o quiasma em lugar do para outro: isso quer dizer que não há apenas rivalidade eu-outrem, mas cofuncionamento. Funcionamos como um único corpo" (MERLEAUPONTY, 2012, p. 200). Daí a importância de substituir a expressão "intersubjetividade" por "intercorporeidade", e a palavra "outro" por "outrem", pois náo se está nunca diante de apenas uma outra unidade constituinte como subjetividade, porém, diante de algo que é o próprio intercorporal, o qual não passa por uma elaboração da consciência. ${ }^{3}$

A consciência nunca tem diante de si uma coisa, ou o outro como objeto que remeta a um processo constitutivo fundado nela enquanto atividade, uma vez que a relação intersubjetiva, ou melhor, intercorporal impede de privilegiar um dos termos da correlação eu-outro, porque a experiência dessa correlação está perpassada por uma experiência de passividade. Trata-se daquela transcendência radical para a qual o ego e o alter ego são apenas seus momentos

2 Notas de trabalho consultadas nos arquivos da Biblioteca Nacional Francesa.

${ }^{3}$ Cabe salientar que a concepçáo de Merleau-Ponty sobre a questão da alteridade foi pensada, nesta pesquisa, em função de dois significantes distintos. O primeiro diz respeito ao outro (autre) como aquele que se apresenta a partir do resultado de uma operaçấo transcendental constitutiva do ego, ou seja, o outro transcendental que é constituído na esfera da pertença, conforme o sentido fenomenológico atribuído por Husserl. O segundo corresponde ao fenômeno outrem (autrui), conforme concebido por Merleau-Ponty, no sentido desse estranho que não é apenas a apresentação do alter ego no campo de presença do ego transcendental, como se houvesse um outro eu fora de mim, mas outrem como alteridade radical que nấo pode ser derivado de uma atividade constituinte. Segundo Merleau-Ponty (2012, p. 187-188), "não compreenderemos jamais que outrem apareça diante de nós; o que está diante de nós é objeto. É preciso compreender bem que o problema não é este. É compreender como me desdobro, como me descentro. A experiência de outrem é sempre a de uma réplica de mim. A solução deve ser procurada do lado dessa estranha filiação que para sempre faz de outrem meu segundo, mesmo quando o prefiro a mim e me sacrifico a ele. É no mais secreto de mim mesmo que se faz a estranha articulação com outrem; o mistério de outrem não passa do mistério de mim mesmo". Ao longo deste trabalho, optou-se por generalizar e utilizar a expressão outrem de forma uniforme, salvo nos momentos em que evidentemente se quis dizer outro, no sentido do outro transcendental. 
expressivos, ou seja, a transcendência do tempo, a qual transforma o passado, o presente e o futuro em uma experiência de unidade, sem a necessidade da atividade constituinte do ego transcendental. A unidade originária, a qual se acredita ser a base da consciência, é transpassada por uma experiência do estranhamento de si mesmo, que é o próprio tempo, ou seja, na experiência da consciência e da existência enquanto um fluxo temporal que os abarca.

De acordo com Merleau-Ponty (2011), em uma nota de novembro de 1959, em $O$ visivel e o invisivel, a relação eu-outro é uma fórmula insuficiente, um problema ocidental que náo seria um problema, se não fosse a noção solipsista de subjetividade constituinte. Na perspectiva carnal de uma relação intercorporal com outrem, marcada pela virtualidade passiva da experiência do tempo, predomina um "polimorfismo fundamental que faz com que eu não tenha que constituir o Outro perante o Ego: ele já lá está, e o Ego é conquistado sobre ele" (MERLEAU-PONTY, 2011, p. 270). A questão que se coloca é a de 'descrever a pré-egologia, o 'sincretismo', a indivisão, transitivismo entre eu e outrem. Que é que existe a este nível? Existe o universo vertical ou carnal e a sua matriz polimorfa" (MERLEAU-PONTY, 2011, p. 270). Trata-se de reconhecer que o tempo, concebido como Gestalt, não exige um cogito como sua condição, nenhum prévio que realize as sínteses temporais, visto tratar-se da percepção de totalidades espontâneas e abertas.

Não há nisso uma atividade da alma, nem uma produção de pensamento no plural, e eu não sou nem mesmo o autor desse vazio que se faz em mim pela passagem do presente à retençáo, não sou eu quem me faz pensar, como não sou eu quem faz meu coração bater. (Deve-se) abandonar assim a filosofia dos Erlebnisse e passar a filosofia da nossa Urstiftung. (MERLEAUPONTY, 2011, p. 271).

Diferentemente de Husserl, que acreditava ser necessário recolocar as estruturas temporais dos mundos vividos no fluxo transcendental, por meio de sínteses operativas da consciência, para superar a ambiguidade da experiência, Merleau-Ponty considera que certa ambiguidade é incontornável. Não enquanto defeito ou falha da experiência em revelar a verdade do mundo, de si, e de outrem, todavia, no sentido de admitir ser justamente tal ambiguidade que garante a espontaneidade, ou seja, a "continuidade enquanto um fluxo de imagens que se sobrepóem, representaçóes que se sobredeterminam, dada a insuficiência de cada qual para esgotar as possibilidades doadas pela outras imagens" (MÜLLER-GRANZOTTO, 2013, p. 366). 
Nesse sentido, ver é captar uma imagem no tempo, que passará a se tornar passado, mas que será retomado e presentificado na configuração da percepção da próxima imagem, não como um ato da consciência, contudo, enquanto espontaneidade oriunda do processo de diferenciação entre imagens. As figuras, eu, outrem ou mundo são ocorrências gestálticas que se diferenciam por um leve descentramento, na medida em que cada qual remete a um fundo temporal transcendente. Daí o sentido da afirmação de Merleau-Ponty sobre a novidade de seu pensamento para a questão de outrem: "posição, negaçáo, negação da negação: este lado, o outro, o outro de outro. O que trago de novo ao problema do mesmo e do outro? Isto: que o mesmo seja o outro de outro, e a identidade diferença de diferença”" (MERLEAU-PONTY, 2011, p. 312).

Entretanto, o que isso significa exatamente? A imagem eu-outro são ocorrências expressas na relação de figura sobre fundo, ou seja, imagens que, por diferenciação, se constituem como identidade. A diferença, portanto, não é apenas entre o ego e o alter ego, pois, se assim fosse, seria necessário admitir que a percepçáo da diferença se deve a uma atividade fundadora da consciência, mas não se trata disso. Enquanto passividade, a diferenciação ocorre, porque cada qual percebe no outro uma diferença com relação a um terceiro, que se apresenta como fundo de generalidade, a partir da qual as duas imagens, o eu e o outro, se encontram entrelaçadas.

\section{Temporalidade E intersubjetividade em Husserl e Merleau-Ponty}

Em O filósofo e sua sombra, texto que marca a transição para a fase final do pensamento do autor, as teses de Husserl são analisadas, considerandose o problema da comunicação, no que concerne ao risco de exagerar na pretensão daquilo que a consciência do leitor pensa saber sobre a do escritor. Seria necessário encontrar um meio termo entre uma "história objetiva da filosofia" e uma "meditação transformada em diálogo", "no qual o filósofo de que se fala e aquele que fala estejam presentes juntos, embora seja, mesmo de direito, impossível diferençar a cada instante o que pertence a cada um" (MERLEAU-PONTY, 2014, p. 260). O que interessa a Merleau-Ponty não é analisar especificamente o pensamento de Husserl, como se fosse possível delimitar exatamente o que ele queria dizer, pois o que torna possível esse diálogo entre escritor e leitor não é tanto o que a gramática da linguagem diz diretamente, mas aquilo para o qual ela abre e que transcende todo e qualquer tipo de categorização. Trata-se do impensado em Husserl, daquela dimensão 
pré-reflexiva sobre a qual ele falava, e num certo sentido pertence a sua tese, todavia, que abre para outras possibilidades de interpretação, ou seja, para a sombra do filósofo.

A reflexão de Husserl, por conseguinte, aponta para o irrefletido que se desvela pela própria atividade da reflexão, o impensado que desponta nos limites do pensar. $\mathrm{O}$ pensamento, enquanto atividade que visa à posse do objeto em si como imanência, pressupôe essa doação originária, a qual se afasta enquanto transcendência, a cada tentativa de domínio pela consciência. O impensado, a sombra de Husserl, diz respeito a essa constituição préteorética do mundo e de outrem, a partir de onde eles podem ser pensados, e para os quais a consciência nunca está presente de forma simultânea, mas sempre um tanto atrasada ou adiantada. Por isso, a necessidade de supor a intencionalidade operante, como aquilo "que anima o tempo, mais velha que a intencionalidade dos atos humanos" (MERLEAU-PONTY, 2014, p. 269). É nesse domínio estranho aos atos da consciência que Merleau-Ponty se aprofundou, em suas últimas obras, o que distinguiu sua compreensão da intersubjetividade transcendental daquela de Husserl, conforme instaurou a vivência de uma temporalidade mítica.

Nessa perspectiva, é preciso ir além de Husserl e da intersubjetividade transcendental, a qual concebe outrem por analogia ao ego transcendental, à medida que estrutura o fenômeno da temporalidade de forma serial, fixando o poder constituinte na subjetividade, pela positividade do tempo presente. Para Merleau-Ponty, outrem não é simplesmente o outro transcendental, o estranho que, de alguma forma, é constituído subjetivamente, mas esse estranho diante do qual não faz sentido supor a atividade constituinte, já que sua característica é o descentramento. Outrem não é esse que aparece "diante de nós; o que está diante de nós é objeto (MERLEAU-PONTY, 2012, p. 185).” É preciso distinguir do outro transcendental, visando explicar que "o contato com outrem não se apoia na analogia que eu possa fazer entre meu poder vidente e o poder vidente de alguém diferente" (MÜLLER-GRANZOTTO, 2015, p. 388).

Desse modo, a intersubjetividade e o fenômeno da expressão artística não podem ser explicados pelo encontro entre duas subjetividades e nem pelo desencontro, porém, com base naquela experiência do estranho que se apresenta como pura passividade, rastro de experiência que se antecipa aos atos da consciência e lhe confere a configuraçáo possível da experiência, pelo descentramento da subjetividade. 
É diante de outrem como outra pessoa, bem como de outrem como o fundo de si mesmo, enquanto transcendência, que se funda a tese de MerleauPonty sobre a questão da alteridade, em seus últimos trabalhos. Trata-se de "outrem como lacuna, e não como 'pensamento' positivo ou nadificação" (MERLEAU-PONTY, 2013a, n.p.). ${ }^{4}$ Há uma alteridade radical de outrem, mas esse outrem não é apenas um objeto para um sujeito, contudo, concerne à dinâmica temporal do sensível, no qual o sistema eu-outrem se insere. $\mathrm{O}$ ego não é senhor de sua história, não domina o passado e nem o futuro, de sorte que seria um ranço solipsista supor a sua instalação no presente, como o faz a teoria da intencionalidade de Husserl. Assim, a análise intencional que visa a explicar a unidade da experiência do tempo, isto é, a vivência do passado e do futuro, no tempo presente, encontra seu limite; "há aí alguma coisa que a analítica intencional não pode apreender, porque não pode elevar-se a essa simultaneidade que é meta-intencional" (MERLEAU-PONTY, 2011, p. 292). Isso significa que a dinâmica do tempo da consciência não pode ser explicada tomando-se por base a própria consciência, visto que os horizontes temporais transcendem o poder constituinte do ego transcendental.

O estranho, para Husserl, está relacionado à experiência de uma dimensão que extrapola os limites do poder constituinte do ego transcendental e apresenta uma espécie de eu mesmo fora de mim, mas vivido no interior do próprio si mesmo, o que ele denomina intersubjetividade transcendental. Tratase de uma realidade que não é obra "da minha atividade sintética de alguma forma privada, mas como de um mundo estranho a mim, 'intersubjetivo', existente para cada um, acessível a cada um em seus 'objetos'” (HUSSERL, 2001, p. 106). O outro como estranho, em Husserl, é a intersubjetividade transcendental, no sentido desse outro percebido na esfera de vinculação do próprio ego como algo que ele não constituiu, todavia, percebeu como lhe sendo uma realidade estranha. $\mathrm{O}$ outro, portanto, não se reduz à condição de objeto constituído pela consciência, como em Descartes, por isso é o outro transcendental, porém, ele só pode ser percebido pela própria consciência, a partir da dinâmica de empatia:

Toda objetividade pressupóe a subjetividade operante, e a subjetividade é ela mesma pré-dada antes de todo conhecimento objetivo, o que é a mesma coisa que uma função da subjetividade; é somente porque ela é isso, dotada de todas as configuraçóes que tornam possível a empatia, que ela pode realizar a empatia. (HUSSERL, 2011, p. 89).

\footnotetext{
${ }^{4}$ Notas de trabalho consultadas nos arquivos da Biblioteca Nacional Francesa.
} 
Conforme Merleau-Ponty, a experiência do estranho nas relaçôes intersubjetivas não diz respeito a essa esfera de vinculação entre o ego e o alter ego, mas outrem enquanto essa possibilidade da vivência de uma transcendência radical, a qual não deriva em hipótese alguma daquilo que pode haver de proximidade ou distanciamento entre duas consciências. Mesmo quando Husserl remete a percepção lateral, percepção de uma lacuna, trata-se sempre de uma percepção real do outro, como se ele estivesse presente em pessoa (MERLEAU-PONTY, 2001). A ideia de uma "transgressáo intencional" provocada pelo estranho, na medida em que é constituída em algum nível pelo ego, não é suficiente para livrar Husserl da acusação de que há um solipsismo comprometedor, em seu idealismo transcendental. Segundo Merleau-Ponty (1998, p. 64), "a descoberta da intencionalidade operante em nenhum momento leva ao abandono da filosofia da Bewubtsein, da constituição, da analítica intencional". Mesmo que, na última fase de seu pensamento, Husserl tenha admitido certa equivalência entre subjetividade e intersubjetividade transcendental, ele não consegue explicar a percepção de outrem, sem partir do ego como unidade básica fundamental.

Essa questáo é central para se distinguir a teoria da intencionalidade de Husserl da teoria da reversibilidade ou quiasma, de Merleau-Ponty, assim como para diferenciar o modo de compreensão da gênese constitutiva do tempo. Conforme foi possível perceber, Merleau-Ponty considera que a necessidade de Husserl pensar dialeticamente o ego e o alter ego, como substancialidades já constituídas, está relacionada a um equívoco sobre a compreensão do decurso temporal, mais precisamente sobre a pressuposiçáo do tempo presente para explicar a apresentação de outrem. O problema é que, na perspectiva do acoplamento ou emparelhamento (Paarung) de Husserl, "só há possibilidade de compreensão no presente (uma espécie de lugar geométrico do eu e do outro) e numa realidade assimilável" (MERLEAU-PONTY, 2001, p. 45).

Segundo Husserl (1983), no fluxo da consciência imanente constitutiva do tempo, realiza-se uma autoaparição, a partir da qual o próprio fluxo pode ser necessariamente captado em seu fluir. Dessa forma, a aparição do fluxo constitutivo do tempo para a consciência denota a preexistência de uma subjetividade absoluta, um ego puro, sem o qual a aparição seria impossível.

O ego puro de Husserl remete a essa unidade fundamental do tempo, em função da qual seria possível explicar a vivência intencional da duraçáo da percepção. Sem essa unidade fundamental, "as sensaçóes desaparecem com os estímulos que as causam: teríamos então uma sucessão de sensações 
sem o pressentimento de um decurso temporal" (HUSSERL, 1983, p. 21). Ao escutar uma música, por exemplo, não seria possível captar sua unidade harmônica fundamental, pois a parte que foi escutada em um instante presente, ao tornar-se passado, perderia sua conexão com o momento atual, ou seja, não haveria o sentido da duração. "Em face do caso de todos esses sons soarem ao mesmo tempo, nenhuma diferença subsistiria" (HUSSERL, 1983, p. 21-22).

No fenômeno do decurso temporal da consciência, cada vivido atual se encontra sempre conectado a vários outros instantes vividos que escoaram, em direção ao passado. Cada escoamento temporal não se perde no passado e nem está presente simultaneamente à consciência. Cada instante que se tornou antigo mantém um vínculo com a atualidade do tempo presente, no sentido de um escoamento que, cuja ligaçáo, por mais longínqua que seja em relação à atualidade da situação, permanece de algum modo como presente. Isso significa que cada instante vivido náo desaparece com a emergência do instante seguinte, mas se doa como perfil ao instante ulterior, constituindo uma sucessão de retençôes.

Conforme Husserl (1983), toda percepçáo se caracteriza por uma espécie de protoimpressão, a qual, por sua vez, se define como um continuum retencional, pois cada ponto posterior é retenção para o ponto anterior. Esses conteúdos retencionais não são, de forma alguma, objetos intencionais e não se encontram disponíveis na consciência, no entanto, justamente, se constituem como doaçóes originárias ao agora atual, permitindo que os objetos possam ser percebidos no tempo. Contudo, é importante notar, conforme a segunda figura, que o fluxo temporal se projeta de maneira contínua para além do último agora atual, constituindo um horizonte protensional, uma espécie de projeção imaginária do fundo de retenções que possibilita o sentido de futuro.

Pensando a continuidade da percepção do som de uma melodia, Husserl (1983, p. 51) explica que "a apreensáo do agora que aparece, do som 'quase que' agora ouvido, funda-se a memória primária do som como que ouvido mesmo agora e a expectativa (protensão) do que está para vir". O que Husserl descreve é o halo temporal que conecta as diferentes dimensóes do tempo na unidade transcendental, a partir da qual o objeto intencional poderá ser constituído. Nesse sentido, "amparada no continuum de instantes retidos, a consciência pode, a cada instante, distinguir entre o que é atual, passado ou porvir” (MÜLLER-GRANZOTTO, 2012, p. 65). Existe, por conseguinte, uma doação originária do tempo, relacionada aos horizontes retencionais e 
protensionais, os quais se oferecem por perfis na modulação da experiência dos objetos no tempo agora.

De acordo com Merleau-Ponty (2011), há um problema na perspectiva husserliana quanto à compreensão de que a unidade do campo de presença (Präsensfeld), na qual se articulam o passado, o presente e o futuro, tenha por base uma imanência fundamental, isto é, um ego puro. Assim, a teoria da intencionalidade husserliana

[...] transforma-se no fio que liga, por exemplo, meu passado a meu presente em seu lugar temporal tal qual foi (e não tal qual o reconquisto por um ato de evocaçáo) a possibilidade desse ato repousa sobre a estrutura primordial da retençáo com encaixamento dos passados um no interior do outro, consciência desse encaixamento como lei. (MERLEAU-PONTY, 2011, p. 225).

Manter o caráter pontual do presente e supor ali um ato categorial da consciência é tornar problemático o próprio fenômeno da retenção, em termos de presença do passado ausente, pois, concebendo o presente como positividade, como ele poderia se tornar passado e manter-se presente à consciência? Quando o sentido do presente é pensado como positividade, ele se transfere para a perspectiva do presente que se tornou passado, caracterizando-o como negatividade pura e tornando problemática a relação temporal entre o passado retido e o presente atual. Assim, o passado só poderia ser representado no instante presente, e não vivido como uma presença original, em função da afirmação de um tempo presente pontual.

Desse modo, Husserl teria reintroduzido, em sua própria teoria sobre a retenção, a cisão entre matéria e forma, justamente o que a noção de retenção visava a superar (BARBARAS, 2001). O problema é que a análise intencional husserliana supóe a existência de uma posição temporal privilegiada do presente, a partir da qual os vividos podem ser distinguidos entre si em termos temporais, por meio de atos representacionais voluntários. Conforme analisa Merleau-Ponty (2011, p. 225), em nota de $O$ visivel e o invisivel,

[o] engano de Husserl é ter descrito o encaixamento a partir de um Präsensfeld considerado como se não tivesse espessura, como consciência imanente: é consciência transcendente, é ser a distância, é duplo fundo de minha vida de consciência, e é o que faz que possa ser Stiftung náo somente de um instante mas de todo um sistema de índices temporais - o tempo (já como tempo do corpo, tempo taxímetro do esquema corporal) é o modelo dessas matrizes simbólicas que são abertura ao ser. 
A inflação do tempo presente, em Husserl, exige uma explicação da gênese constitutiva do tempo, apoiada no papel ativo de uma síntese intelectual, a qual uniria os vários pontos, permitindo a consciência do tempo e a constituição do objeto intencional. Para Merleau-Ponty (2011), a atuação do ego transcendental husserliano na síntese constitutiva do tempo náo apenas é dispensável, como sua afirmação coloca em questão o fenômeno da retenção como virtualidade possível, pela positivação de cada momento e o privilégio simbólico do tempo presente.

De acordo com Merleau-Ponty (2011), o tempo é uma Gestalt, uma totalidade sem síntese, ou, ainda, um fundo de indivisão em que o próprio presente é concebido na relação figura e fundo. Logo, a coisa espacial e temporal náo é correspondência a si, mas transcendência que se abre para um fundo indeterminado. A linearidade do diagrama temporal husserliano e sua descrição da retenção acabam ignorando esse fato e tornando inviável a explicação sobre a passagem ao horizonte das retenções afastadas, ou seja, sobre o esquecimento, porque necessita de um elemento pontual, fixado no tempo, para efetivar o processo de diferenciaçáo entre os momentos passados mais antigos e os mais recentes. É preciso compreender os horizontes temporais e as possibilidades de permanência do passado como retenção, da mesma maneira que o retorno desse passado como síntese passiva. Isso significa que os perfis retidos e apresentados na perspectiva de um fluxo temporal não podem ser oriundos da capacidade subjetiva de reuni-los, já que a subjetividade se confunde com o próprio fluxo.

A coincidência entre temporalidade e subjetividade enquanto saberes de si não significa redução de um ao outro, como se o tempo só existisse em função da consciência constituinte, conforme revela a análise sobre a questão do esquecimento, proposta em $O$ visivel e o invisivel. Evitando a concepçáo serial do tempo, o filósofo coloca em evidência o caráter descontínuo do esquecimento, o qual faz com que instantes há muito tempo passados possam estar mais vivos à consciência do que instantes recentes. Como explicar essa descontinuidade, se o esquecimento for concebido como contínuo acúmulo de experiências temporais passadas? Será preciso admitir que a temporalidade é autoconstituinte, não sendo a subjetividade responsável por sua aparição. O problema do esquecimento provém de sua descontinuidade temporal, sendo a percepção um modo de diferenciação entre os campos de presença, e o esquecimento um processo de desdiferenciação, por meio do qual os horizontes retidos não podem ser distinguidos um do outro. 
Diferentemente do que o filósofo propunha, na Fenomenologia da percepção, em $O$ visivel e o invisivel, Merleau-Ponty convida a pensar o tempo com base na própria simultaneidade entre o passado e o presente, sem a necessidade de que todo o passado seja uma modificação de um presente já vivenciado, pois isso seria reduzir a temporalidade a uma linha contínua de desenvolvimento. Eis justamente o que a compreensão do tempo como Gestalt almeja demonstrar como sendo inviável, e que a descontinuidade da dinâmica do esquecimento ilustra. Em última instância, a experiência do tempo e a subjetividade se caracterizam pela transcendência, em termos de abertura ao mundo e a outrem. Nem o sujeito nem a dimensão do tempo podem ser concebidos fora da perspectiva gestáltica da figura sobre fundo. Isso significa que ter consciência não é coincidir com o objeto, pois, enquanto transcendência, o presente não é apenas uma abertura em direção ao passado, mas "uma presença a Si que é uma ausência de si, contato com Sigo pela distância em relação a Si - figura sobre fundo, 'Etwas' o mais simples - a Gestalt tem a chave do espírito” (MERLEAU-PONTY, 2011, p. 243).

Do mesmo modo que a percepção do tempo decorrido, enquanto apreensão do processo de decaimento das retençôes e a possibilidade de distingui-las ou unificá-las, não depende do poder constituinte, a percepção de outrem também não. Levando-se em conta a maneira como Husserl descreve o processo genético de constituição da temporalidade e da subjetividade, acentuando o papel da dimensão presente na diferenciação ou identificação dos vividos antecedentes e consequentes, compreende-se sua dificuldade em relativizar o papel do ego transcendental e em admitir, conforme a expressão emblemática de Merleau-Ponty (2011, p. 241), de que "o presente absoluto que sou é como se não fosse" ou "que a linguagem nos tem e não somos nós que temos a linguagem. Que é o ser que fala em nós e não nós que falamos do ser".

Embora sejam formas aparentemente mais poéticas de se referir à relação eu-mundo-outrem, tais expressóes resguardam o sentido do fenômeno da transcendência, na perspectiva dessa indeterminação sobre onde um começa e onde o outro termina, e da abertura de cada um deles a um fundo inesgotável de sentido que não é constituído de modo algum. A cada ato perceptivo ou a cada tentativa de fixar uma expressão no tempo, quer seja o ego, quer o mundo ou outrem, nunca se tem diante de si uma objetividade, algo "em si”, do qual a consciência seria o "para si”. Nesse sentido, a explicação da transcendência depende de uma concepção do "para si" que o atesta como algo 
incontornável, mas que o engloba por um processo de diferenciação de caráter passivo, ou seja, sem a atividade da consciência, pois a própria consciência é um desdobrar-se dessa passividade:

O próprio para-si como caráter incontestável, mas derivado: é a culminação da distância na diferenciação - Presença a si é presença ao mundo diferenciado - A distância perceptiva como fazendo a 'visão' tal como está implicada no reflexo, por ex. - e fechando ser para si pela linguagem como diferenciação. Ter consciência = ter uma figura sobre um fundo - não se pode recuar mais longe. A transcendência da coisa obriga-nos a dizer que somente é plenitude sendo inesgotável, isto é, não sendo inteiramente atual sob o olhar - mas promete essa atualidade total, já que está aí... (MERLEAU-PONTY, 2011, p. 242).

Eis justamente o que Husserl não pôde admitir, dada sua fixação na presença de um si-mesmo indeclinável em suas explicaçóes sobre a gênese constitutiva do tempo e da intersubjetividade, e que Merleau-Ponty visa a superar, em seus últimos textos, refletindo sobre o elemento passivo da gênese constitutiva. Essa passividade não é o contrário de uma atividade, contudo, ela a engloba enquanto possibilidade gestáltica. Segundo Lefort (2003), no prefácio dos cursos sobre a Instituição e passividade, a questão da passividade se apresenta como tentativa de descrever a dimensão em que o caráter ativo e passivo do cogito está integrado em uma experiência mais originária do mundo e de outrem.

\section{OUtrem e o Logos do MUNDo estéTICo}

O entrecruzamento do olhar revela uma invisibilidade que se impóe como aquele fundo que se apresenta qual resto ou rastro de experiência, e se caracteriza pela vivência de uma realidade estranha que precede as deliberaçóes da consciência, portanto, outrem, no sentido de que a correlação eu-outro é transpassada por uma alteridade radical. Trata-se da mesma experiência que se evidencia pela análise da atividade do artista, no sentido de que, em determinados momentos, a pintura gera o descentramento da subjetividade constituinte, e qualquer resquício da tomada de decisão sobre os próximos traços, movimentos ou cores é suspenso por um instante.

Considerando o fenômeno da expressão artística, "no fundo imemorial do visível algo se mexeu, se acendeu, algo que invade seu corpo, e tudo que ele pinta é uma resposta a essa suscitação, sua mão não é senão o instrumento 
de uma longínqua vontade" (MERLEAU-PONTY, 2009, p. 44). Na pintura, portanto, a partir da relação do artista com a sua obra, é possível perceber essa espécie de precessão que, por vezes, o invade como uma presença estranha e o destitui de seu papel central no processo de criação, porque "essa precessão do que é sobre o que se vê e faz ver, do que se vê e faz ver sobre o que é, é a própria visão" (MERLEAU-PONTY, 2009, p. 45). Assim, pela visão, nunca se está diante de um objeto puro, isolado de seu entorno, do mesmo modo que a intersubjetividade não pode ser pensada simplesmente em funçáo da relação entre ego e alter ego.

O que a experiência da pintura ajuda a perceber é o momento no qual essa espécie de antecipação ao sentido da visão, do falar, do pensar ou do mover-se se caracteriza pela vivência de uma presença estranha. Trata-se desses momentos em que o sujeito e o objeto se confundem, quando não é possível estabelecer limites rigorosos entre o ego e o alter ego, pelo fato de ambos serem arrastados, ou melhor, descentrados por uma força instituinte, diante da qual ambos são passivos. "A pintura não foi criada apenas pelo pintor. Ela, por si só, possui uma dimensão passiva. $\mathrm{O}$ artista precisa estar aberto a essa dimensão de passividade, como uma espécie de espontaneidade criadora" (BITENCOURT, 2015, p. 164).

Tem-se, portanto, uma atividade que, enquanto fenômeno expressivo, revela a presença de um Logos mais originário, de um mundo natural que o pensamento objetivo e a análise reflexiva náo reconhecem, um Logos do mundo estético, como estabeleceu Husserl e ressignificou Merleau-Ponty:

Quando o reconhecimento do mundo vivido, e portanto também da linguagem vivida, torna-se, como nos últimos escritos, característica da fenomenologia, isso é apenas uma maneira mais resoluta de expressar que a filosofia náo está imediatamente de posse da verdade da linguagem e do mundo, que é antes a recuperação e a primeira formulação de um Logos esparso em nosso mundo e em nossa vida, ligado a suas estruturas concretas - esse 'Logos do mundo estético' de que já falava a Logica formal e transcendental. (MERLEAU-PONTY, 1991, p. 113).

Essa realidade é, para Merleau-Ponty, o que dá sentido ao fenômeno da expressão artística, uma espécie de camada da existência, que se manifesta como precessão e que favorece a explicação do fenômeno do entrelaçamento entre o artista e sua obra, bem como entre eu e outrem, pela intersubjetividade. $\mathrm{Na}$ definição dada por Merleau-Ponty (2009, p. 492), o Logos do mundo estético 
é "uma 'arte escondida nas profundezas da alma humana', e que, como toda arte, só se conhece em seus resultados." Pela dinâmica do descentramento, esse Logos está relacionado à vivência de uma dimensão da temporalidade que é mítica, uma vez que não pode ser transformada em idealidade e pensada como séries temporais. "Introduz-se o ser 'selvagem' ou 'bruto' - ultrapassase o tempo serial, o dos 'atos' e das decisões - reintroduz-se o tempo mítico" (MERLEAU-PONTY, 2011, p. 220), o tempo como o estranho, como outrem.

$\mathrm{Na}$ relação do pintor com sua obra, assim como entre eu e outro, manifesta-se a experiência de uma reversibilidade que faz diluir qualquer distinção radical entre os polos da dualidade, preservando a impossibilidade de fundi-los definitivamente. $\mathrm{O}$ artista, diante da tela ou daquilo que ela representa como imagem, interage de modo a colocar em marcha um processo em que a atividade da consciência enquanto ato de ver e expressar-se se deflagra com a vivência de uma passividade a si como estranho. A forma como Cézanne fala da expressão artística na pintura revela justamente essa relação do artista com sua obra, a qual transcende os limites da distinção clássica do sujeito e do objeto.

De acordo com Merleau-Ponty (1966, p. 20), Cézanne "não quer separar as coisas fixas que nos aparecem ao olhar de sua maneira fugaz de aparecer, quer pintar a matéria ao tomar forma, a ordem nascendo por uma organização espontânea.” E, para que isso aconteça, é necessário supor uma relação de imbricação (empiètement) entre o artista e sua obra, bem como o salto (enjambement) dessa camada invisível da existência por meio da expressão. "A paisagem, dizia, se pensa em mim e sou sua consciência. Nada está mais distante do naturalismo que esta ciência. A arte não é uma imitação, nem, por outro lado, uma fabricação segundo os votos do instinto e do bom gosto. É uma operação de expressão" (MERLEAU-PONTY, 1966, p. 24).

Quando o artista inicia o processo da pintura e, após certo tempo, percebe-se como que tendo a mão conduzida por um estranho, enquanto seus pensamentos divagam por outros mundos, ele está vivenciando a alteridade do fluxo contínuo do tempo, a partir do qual as imagens podem emergir por meio de um ato criador. $\mathrm{O}$ modo de Cézanne se referir ao trabalho do artista coloca em evidência essa dimensão do tempo mítico que destaca Merleau-Ponty, um Logos do mundo estético que permite que uma obra de arte seja apreciada por outros observadores. O talento do artista diz respeito a sua capacidade de 
comunicar, de fazer sentir a sua experiência, diante da paisagem, por outros observadores:

Um pintor como Cézanne, um artista, um filósofo devem não somente criar e exprimir uma idéia, mas ainda despertar as experiências que a vão enraizar em outras consciências. Se a obra é bem sucedida, tem o estranho poder de transmitir-se por si. Seguindo as indicaçóes do quadro ou do livro, tecendo comparaçóes, tateando de um lado e de outro, conduzido pela confusa, clareza de um estilo, o leitor ou o espectador acaba por reencontrar o que se lhe quis comunicar. O pintor só pode construir uma imagem. É preciso esperar que esta imagem se anime para os outros. Então a obra de arte terá se unido a essas vidas separadas, não existirá mais em apenas uma delas como um sonho tenaz ou um delírio persistente, ou no espaço como uma tela colorida, ela viverá indivisa presumivelmente em todas as mentes possíveis, como uma aquisição para sempre. (MERLEAUPONTY, 1966, p. 27).

Desse modo, a obra de arte se coloca numa dimensão da intersubjetividade que está para além de uma comunicação face a face, na medida em que o ego individual é descentrado por um terceiro, ao qual não se tem acesso por um ato da consciência, entretanto, que emerge do subterrâneo da existência da própria consciência enquanto temporalidade. A pintura não é fruto de uma atividade da consciência do artista, mas antes de uma passividade que se revela como algo espontâneo e criador, que tira o protagonismo da subjetividade constituinte e se impóe como uma alteridade radical, fazendo com que as posiçôes entre o vidente e o visível, o tocante e o tocado se invertam momentaneamente, a ponto de se confundirem entre si. De acordo com Merleau-Ponty (2006, p. 16), "uma vez dado esse estranho sistema de trocas, todos os problemas da pintura aí se encontram".

O mesmo poderia ser dito com relação ao problema da intersubjetividade, pois a forma carnal da presença da arte e de outrem só se torna compreensível, tendo-se em vista esse transitivismo. Em certo sentido, a carnalidade das imagens na pintura é a mesma carnalidade de outrem na intersubjetividade, no sentido da possibilidade de inversão dos papéis, conforme resgata MerleauPonty (2006, p. 23), quanto à expressão de André Marchand de se sentir observado pela floresta, enquanto a observava para pintar. Essa inversão de papéis, a qual ocorre tanto na relaçáo do artista com a paisagem quanto na relação entre ego e alterego, opera como um jogo de espelhos, "uma universal magia que transforma as coisas em espetáculos, os espetáculos em coisas, eu em outrem e outrem em mim" (MERLEAU-PONTY, 2006, p. 25). 


\section{ConsideraçốES FINAIS}

De acordo com o que se pretendeu analisar neste trabalho, na filosofia da alteridade de Merleau-Ponty outrem, é essa impossibilidade de acabamento revelada pela experiência da intercorporeidade, na medida em que cada corpo guarda uma invisibilidade para si que é visível para outrem. Nesse sentido, há algo de si mesmo a que não se tem acesso, pois é acessível apenas a outro olhar, como se houvesse um pouco do eu em outrem e de outrem no eu. Intercorporeidade seria essa experiência pela qual se faz possível perceber que é "em mim que outrem se completa e nele eu me completo" (MERLEAU-PONTY, 2013b, p. 102). No momento em que dois olhares se cruzam, por pouco mais que apenas um instante, constitui-se a experiência de estranhamento caracterizada pela ausência de limites bem definidos entre ego e alter ego, como se existisse algo de si como outrem.

Existe, portanto, uma conexão profunda nessa relação, visto que "uma parte de mim está nele” (MERLEAU-PONTY, 2013b, p. 103). Contudo, isso não significa justaposiçáo ou identidade plena, porque o que há em outrem é justamente uma visão sobre mim que me falta. "Assim, não se é só, nem dois, mas si mesmo em outrem e outrem em si" (MERLEAU-PONTY, 2013b, p. 103). Quando dois olhares se fixam, a dicotomia eu-outro se torna problemática, pois se evidencia o entrelaçamento qual quiasma que impede a distinção plena entre eles, no sentido de duas subjetividades constituintes. Nessa perspectiva, não é possível falar em constituição do alter ego pelo ego, visto que a "consciência de outrem é tão imediata quanto a de si mesmo" (MERLEAU-PONTY, 2013, p. 104).

Desse modo, essa forma de conceber as relações intersubjetivas vai ao encontro da compreensão de Merleau-Ponty sobre a expressão artística. Em ambos os casos, é preciso recorrer a uma dimensão originária da existência, um Logos do mundo estético que o filósofo retomou, a partir das leituras de Husserl, e aprofundou, em direçáo à carnalidade do mundo e de outrem. Tanto na pintura como na intersubjetividade, ocorre a metamorfose do vidente no visível, por meio de uma reversibilidade, tal como um jogo de espelhos, o qual revela a experiência de outrem como estranho, como um fantasma. Segundo "o fantasma do espelho puxa para fora minha carne, e ao mesmo tempo todo o invisível de meu corpo pode investir os outros corpos que vejo. [...], o homem é espelho para o homem" (MERLEAU-PONTY, 2006, p. 25). Eis um fenômeno que precisa ser considerado, para se compreender as relaçóes 
intersubjetivas, inclusive no que se refere à intersubjetividade intermediada pela arte.

ALVARENGA, R. The carnality of otherness and the logos of the aesthetic world in MerleauPonty. Trans/formlação, Marília, v. 43, n. 4, p. 313-336, Out./Dez., 2020.

\begin{abstract}
The question of intersubjectivity is present throughout the work of Merleau-Ponty, since The structure of behavior, from the debate with classical psychology and physiology, to the indirect ontology developed in The visible and the invisible. His theses evidence a deepening toward the carnality of otherness as the experience of a stranger / family member, who is central to understanding the possibility of intersubjectivity and the aesthetic experience of the world. Thus, the present study aims to understand how Merleau-Ponty developed his theory of intersubjectivity in the last phase of his thinking, considering the existing relationship between the experience of otherness and the artistic experience, from the Logos of the aesthetic world.
\end{abstract}

Keywords: Alterity. Art. Flesh. Otherness

\title{
REFERÊNCIAS
}

BARBARAS, R. De l' être du phénomène: sur l'ontologie de Merleau-Ponty. Grenoble: ÉditionsJérômeMillon, 2001.

BITENCOURT, A. C. Olhar e passividade na pintura segundo Merleau-Ponty. 2015. 276 f. Tese (Doutorado) - Universidade Federal de Santa Catarina, Florianópolis, 2015.

CARDIM, L. A ambiguidade na Fenomenologia da percepçáo de Maurice MerleauPonty. 199 f. Tese (Doutorado) - Universidade Federal de São Carlos, São Carlos, 2007.

FALABRETTI, É. S. A presença do Outro: intersubjetividade no pensamento de Descartes e de Merleau-Ponty. Revista de Filosofia Aurora, v. 22, n. 31, p. 515-541, 2010.

HUSSERL, E. Leçons pour une phénoménologie de la conscience intime du temps. Traduit par Henri Dussort. France: Presses Universitaires de France, 1983.

HUSSERL, E. Sur l'intersubjectivité. Traduction par Natalie Depraz. Paris: Universitaires de France, 2001. v. 1.

LEFORT C. Prefácio. In: MERLEAU-PONTY, M. Oeuvres. Paris: Gallimard, 2010. LEFORT C. Notes. In: MERLEAU-PONTY, M. L'institution e La Passivité: Notes de Cours au Collège de France (1954-1955). Paris: Belin, 2003. 
JOHNSON, G. A; SMITH, M. B. (Eds.). Ontology and alterity in Merleau-Ponty. Illinois: NorthwesternUniversity, 1990.

MERLEAU-PONTY, M. Sens et non sens. 5ª ed. Paris: Les éditions Nagel, 1966. (Collection Pensées).

MERLEAU-PONTY, M. Notes de cours au Collége de France (1959-1961). Paris: Gallimard, 1996.

MERLEAU-PONTY, M. Notes de cours sur l'origine de la géométrie de Husserl (1959-1960). Paris: PUF, 1998.

MERLEAU-PONTY, M. Psychologie et pédagogie de l'enfant: cours de Sorbonne (1949-1952). Lagrasse: Verdier, 2001.

MERLEAU-PONTY, M. L'institution e La Passivité: Notes de Cours au Collège de France (1954-1955). France: Belin, 2003.

MERLEAU-PONTY, M. L'oeil et l'esprit. Paris: Gallimard, 2006.

MERLEAU-PONTY, M. La Nature ou le monde du silence. Paris: Hermann, 2008. MERLEAU-PONTY, M. Phénoménologie de la perception. Paris: Gallimard, 2009. MERLEAU-PONTY, M. Le visible et l'invisible. Paris: Gallimard, 2011. (Collection Tel).

MERLEAU-PONTY, M. La prose du monde. Paris: Gallimard, 2012.

MERLEAU-PONTY, M. Manuscrits non publiés. Bibliothèque Nationale de France. Paris:[s.n.], 2013a.

MERLEAU-PONTY, M. Recherches sur l'usagelittéraire du langage: cours au Collège de France. Notes. 1953. Genève: MetisPresses, 2013b.

MERLEAU-PONTY, M. Signes. Saint-Amand: Gallimard, 2014. (Folio/Essais).

MÜllER-GRANZOTTO, M. J.; MÜLLER-GRANZOTTO, R. L. Clínicas gestálticas: sentido ético, político e antropológico do self. São Paulo: Summus, 2012.

MÜLlER-GRANZOTTO, M. J.; MÜLLER-GRANZOTTO, R. L. Outrem em Husserl e em Merleau-Ponty. In: BATTISTI, C. A. (Org.). As voltas com a questão do sujeito: posições e perspectivas. Cascavel: Unijuí, Edunioeste, 2010. (Coleção filosofia). THIERRY, Y. Du corps parlant: le langage chez Merleau-Ponty. Grèce: K. Mihalas, 1987.

Recebido: 01/10/2019

Aceito: $12 / 02 / 2020$ 
ALVARENGA, R. 